\title{
Effect of Machine Smoking Intensity and Filter Ventilation Level on Gas-Phase Temperature Distribution Inside a Burning Cigarette*
}

\author{
by \\ Bin Li ${ }^{1}$, Lucan Zhao ${ }^{l}$, Chuanfang Yu ${ }^{l}$, Chuan Liu ${ }^{2}$, Yi Jing ${ }^{1}$, Hongrui Pang ${ }^{l}$, Bing Wang ${ }^{1}$, and Kevin G. McAdam ${ }^{2}$ \\ ${ }^{1}$ Zhengzhou Tobacco Research Institute of CNTC, Zhengzhou 45000, China \\ ${ }^{2}$ British American Tobacco, Group Research \& Development, Regents Park Road, Southampton SO15 8TL, UK
}

\section{SUMMARY}

Accurate measurements of cigarette coal temperature are essential to understand the thermophysical and thermochemical processes in a burning cigarette. The last systematic studies of cigarette burning temperature measurements were conducted in the mid-1970s. Contemporary cigarettes have evolved in design features and multiple standard machine-smoking regimes have also become available, hence there is a need to re-examine cigarette combustion. In this work, we performed systematic measurements on gas-phase temperature of burning cigarettes using an improved fine thermocouple technique. The effects of machine-smoking parameters (puff volume and puff duration) and filter ventilation levels were studied with high spatial and time resolutions during single puffs. The experimental results were presented in a number of different ways to highlight the dynamic and complex thermal processes inside a burning coal. A mathematical distribution equation was used to fit the experimental temperature data. Extracting and plotting the distribution parameters against puffing time revealed complex temperature profiles under different coal volume as a function of puffing intensities or filter ventilation levels. By dividing the coal volume prior to puffing into three temperature ranges (lowtemperature from 200 to $400^{\circ} \mathrm{C}$, medium-temperature from 400 to $600{ }^{\circ} \mathrm{C}$, and high-temperature volume above $600{ }^{\circ} \mathrm{C}$ ) by following their development at different smoking regimes, useful mechanistic details were obtained. Finally, direct visualisation of the gas-phase temperature through detailed temperature and temperature gradient contour maps provided further insights into the complex thermophysics of the burning coal. [Beitr. Tabakforsch. Int. 26 (2014) 191-203]

KEYWORDS: Cigarette, coal temperature, filter ventilation, machine smoking

\section{ZUSAMMENFASSUNG}

Präzise Messungen der Temperatur der Zigarettenkohle sind unabdingbar, um die thermophysikalischen und thermochemischen Prozesse in einer brennenden Zigarette verstehen zu können. Die letzten systematischen Studien zu Temperaturmessungen bei brennenden Zigaretten wurden Mitte der 1970er Jahre durchgeführt. Die heutigen Zigaretten haben sich in ihren Konstruktionsmerkmalen weiterentwickelt und es stehen inzwischen mehrere Standardprotokolle für Rauchmaschinen zur Verfügung. Daher muss die Zigarettenverbrennung neu untersucht werden. In der vorliegenden Arbeit wurden mithilfe einer verbesserten Feindraht-Thermoelement-Technik systematische Messungen der Temperatur der Gasphase von brennenden Zigaretten durchgeführt. Die Auswirkungen maschineller Abrauchparameter (Zugvolumen und Zugdauer) sowie des Filterventilationsgrads wurden mit hoher räumlicher und zeitlicher Auflösung während einzelner Züge untersucht. Die Versuchsergebnisse wurden auf verschiedene Arten präsentiert, um die dynamischen und komplexen thermischen Prozesse in der brennenden Kohle herauszustellen. 
Die experimentellen Temperaturdaten wurden in eine mathematische Verteilungsgleichung eingefügt. Die Extraktion und Darstellung der Verteilungsparameter in Gegenüberstellung zur Zugzeit ergaben komplexe Temperaturprofile bei unterschiedlichem Kohlevolumen in Abhängigkeit von der Zugintensität bzw. dem Grad der Filterventilation. Durch eine Unterteilung des Kohlevolumens vor dem Ziehen in drei Temperaturbereiche (niedrig von 200 bis $400{ }^{\circ} \mathrm{C}$, mittel von 400 bis $600{ }^{\circ} \mathrm{C}$ und hoch über $600^{\circ} \mathrm{C}$ ) und durch die Untersuchung ihrer Entwicklung bei unterschiedlichen Rauchprotokollen wurden hilfreiche mechanistische Daten erhoben. Die direkte Visualisierung der Gasphasentemperatur durch detaillierte Temperatur- und Temperaturgradienten-Konturkarten lieferte weitere Erkenntnisse zur komplexen Thermophysik brennender Kohle. [Beitr. Tabakforsch. Int. 26 (2014) 191-203]

\section{RESUME}

Des mesures précises de la température du charbon des cigarettes sont essentielles pour comprendre les processus thermophysiques et thermochimiques dans une cigarette allumée. Les dernières études systématiques traitant des mesures de la température de combustion des cigarettes ont été menées au milieu des années 70. Les cigarettes contemporaines ont évolué sur le plan de leur conception et de multiples régimes standards de fumage par machine sont désormais disponibles; il y a donc un besoin de réexaminer la combustion des cigarettes. Dans le cadre des présents travaux, nous avons réalisé des mesures systématiques de la température en phase gazeuse de cigarettes allumées, en utilisant une technique améliorée de thermocouple fin. Les effets des paramètres de fumage par machine (volume et durée des bouffées) et les niveaux de ventilation des filtres ont été étudiés avec des résolutions spatiales et temporelles élevées au cours de bouffées uniques. Les résultats expérimentaux ont été présentés de différentes manières pour mettre en évidence les processus thermiques dynamiques et complexes à l'intérieur d'un charbon incandescent. Une équation mathématique de distribution a été utilisée pour décrire les données des températures expérimentales. L'extraction et la représentation graphique des paramètres de distribution par rapport à la durée de la bouffée ont révélé des profils de température complexes avec différents volumes de charbon en fonction des intensités des bouffées ou des niveaux de ventilation des filtres. La division $\mathrm{du}$ volume de charbon en trois plages de températures préalables à la bouffée (volume à températures basses de 200 à $400{ }^{\circ} \mathrm{C}$, volume à températures moyennes de 400 à $600{ }^{\circ} \mathrm{C}$ et volume à températures élevées au-dessus de $600{ }^{\circ} \mathrm{C}$ ) et le suivi de leur évolution dans le cadre de différents régimes de fumage ont permis d'obtenir des informations mécaniques utiles. Finalement, une visualisation directe de la température en phase gazeuse au moyen de cartes de températures détaillées et de courbes de gradients de température a fourni des indications supplémentaires concernant la thermophysique complexe $\mathrm{du}$ charbon incandescent. [Beitr. Tabakforsch. Int. 26 (2014) 191-203]

\section{INTRODUCTION}

Cigarette smoking is known to cause a number of grave diseases. The only way to avoid smoking related diseases is not to smoke. Within this context, a better understanding of the main physicochemical processes responsible for smoke formation may help to reduce the levels of toxicants in smoke (1-3). Cigarette smoke is a complex aerosol system (4-6), so far over 6,000 substances have been identified in tobacco smoke. The constituents in smoke are mainly formed as the result of incomplete combustion of tobacco, which is an agricultural biomass with almost equal compositional complexity (7). A lit cigarette will experience one or two types of burn, smouldering and puffing. A puffing burn can induce fast temperature rises up to $950{ }^{\circ} \mathrm{C}$ in the presence of air influx. Oxidative and pyrolytic decomposition of the tobacco ensues, followed by condensation, coagulation and filtration, resulting in a supersaturated aerosol plume.

Studying the cigarette combustion processes begins with systematic measurements of combustion temperatures inside the burning cigarette (8-10). Puffing causes a rapid and transient heat release, and mass transfer occurring in the porous tobacco rod, both solid-phase and gas-phase temperatures have to be measured to fully characterize this important aspect of thermophysics (11-13). The gas-phase temperatures are typically measured by fine thermocouples inserted inside the burning cigarette, the solid-phase temperature on the other hand has to be measured with fine optical temperature sensors $(11,12)$. Detailed and systematic measurements of the two types of combustion temperature were first obtained by BAKER $(11,12)$, and the results have served as the basis of understanding overall smoke formation mechanism inside a burning cigarette.

Modern cigarettes have gradually evolved since the 1970s, with some new technological features introduced to meet consumer preference and tobacco regulation requirements (1). For example, the addition of expanded tobacco (14) and reconstituted tobacco sheet materials are now common in order to reduce machine-smoked mainstream smoke "tar" levels (15). The cigarette wrapping paper has become more porous to encourage diffusion of small molecule gases and volatile organics out of the tobacco rod (16). The overwhelming majority of cigarette filters have used air ventilation to dilute mainstream smoke and some also contain adsorbents such as charcoal (16-19). Novel cigarettes that primarily heat rather than burn tobacco have also been launched commercially (20). Furthermore, different machine-smoking regimes, such as the one proposed by Health Canada, have been proposed in addition to the most widely used ISO smoking parameters (21) in order to cover a wider range of smoking conditions (5). All these facts mean that commercial cigarettes in the market now are different from those used to build the knowledge. Combining these changes with the different smoking protocols proposed to cover a set of more intense smoking parameters (21), there is a need to re-examine the basic thermophysical parameters for modern cigarettes to ensure that our understanding remains valid. 
Temperature distributions inside a burning cigarette as a function of puffing parameters is arguably one of the most fundamentally important parameters underpinning smoke generation. Under natural smouldering condition, the solids and gases within the burning coal achieve a near equilibrium temperature (8). However, when a puff is applied, forced air influx drives the solid and convective gases to adopt different temperatures. Gas-phase and solid-phase temperatures have to be separately measured by different techniques $(11,12)$. For the gas-phase temperature, this is commonly (but not routinely) measured using fine thermocouples inserted inside a tobacco rod. During a puff, ambient air is drawn into a cigarette, causing the burning zone to move forward. Multiple temperature profiles are recorded by an array of thermocouples and subsequently reconstructed to obtain a series of temperature evolution maps $(11,12)$. Gas-phase temperature is related to cigarette pressure drop or convective flow within the tobacco rod (22), and hence is a key factor controlling the draw resistance as well as heat and mass transfer.

Accurate and reproducible measurements of temperature variations within cigarettes by fine thermocouples are seemingly simple but practically demanding. Suitable temperature sensors have to have a wide response range (from ambient to ca. $1,000{ }^{\circ} \mathrm{C}$ ) and be able to capture fast temperature changes up to $500{ }^{\circ} \mathrm{C} \mathrm{s}^{-1}$. Small diameter thermocouples are typically used for the task, because they have low thermal mass and physical dimensions which help to reduce any possible interference to the combustion process. The diameter of the thermocouples used are usually between 0.1 to $0.25 \mathrm{~mm}$. In early studies, Type-R thermocouples (platinum rhodium $-13 \%$ / platinum) were used which have a temperature range from 0 to $1,600{ }^{\circ} \mathrm{C}$ $(8,11,12)$. In more recent studies, it has been common to use Type-K (chromel / alumel) covering $-200{ }^{\circ} \mathrm{C}$ to $+1,250{ }^{\circ} \mathrm{C}$. Both types have fast temperature responses covering the cigarette coal temperature range. It is also known that violent transient combustion events exist in a burning coal (8), these are beyond the resolution of the thermocouple technology. On the whole, these events do not affect the apparent average temperature of the coal, hence are not normally measured.

In this work, significant efforts were made to automate the operational procedures, which have improved the accuracy and operational ability of the technique. We have used this technique to study the combustion behaviour of a so-called reduced ignition propensity cigarette (23) and the effect of an earlier puff on a subsequent puff (24). In this paper, we examine the highly dynamic nature of a burning cigarette coal from its gas-phase temperature under different puffing parameters and present a systematic approach to understand cigarette coal combustion.

\section{EXPERIMENTAL}

\section{Thermocouple insertion}

Accurate thermocouple positioning inside a cigarette is essential to ensure repeatable temperature measurements. A dedicated thermocouple insertion system (Figure 1) was developed to allow multiple fine thermocouples to be inserted inside a cigarette with good accuracy. The system has been described before $(23,24)$. Briefly, a test cigarette is loaded into its holder and supported by the block along its length. The cigarette position from the lighting end is then read by the control software to within $\pm 0.01 \mathrm{~mm}$. Preset measurement locations on the tobacco rod are selected. A sharp insertion needle creates one hole at a time according to pre-defined position. This action is repeated until up to eight thermocouples are positioned. Any effect of $8 \mathrm{~K}$ type $0.254 \mathrm{~mm}$ diameter thermocouples inserted up to the depth of $4 \mathrm{~mm}$ on the burning cigarette is considered negligible. A starch-based paper glue is applied manually to seal the perforation around the thermocouples. Before starting temperature measurements, the supporting block is removed.

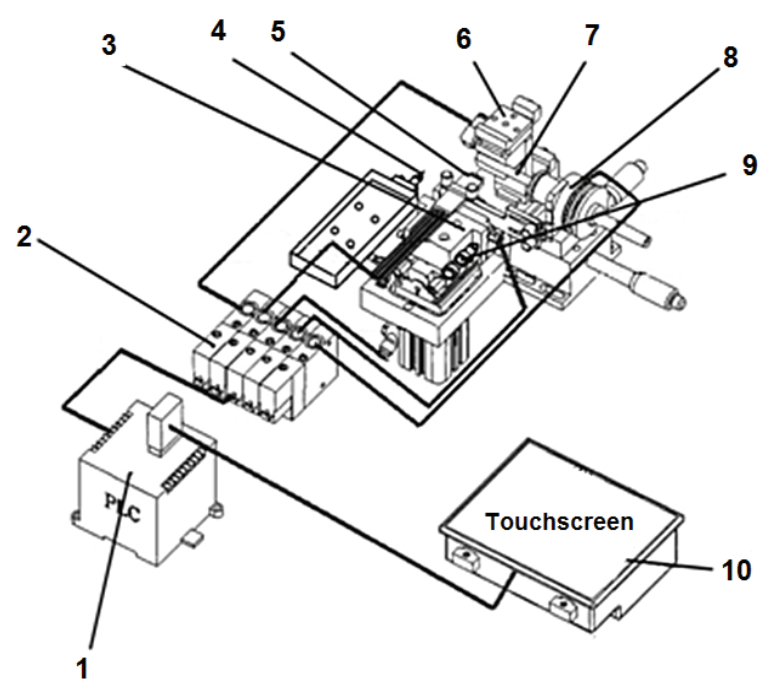

Figure 1. The thermocouple insertion system used in this study. 1. PLC (programmable logic controller); 2. execution unit of programmable logic controller; 3. thermocouple carrier; 4. precision piecing needle; 5 . thermocouple array; 6 . cigarette support during insertion; 7. test cigarette; 8 . the connection to a smoking machine; 9. a $X-Y$ positioning stage; 10. a computer to control insertion according to pre-defined grid positions.

Figure 2 shows that the thermocouple insertion grids, ca. $2 \mathrm{~mm}$ apart, along the rod length and $0.97 \mathrm{~mm}$ apart in cross-sectional depth. Due to axial symmetry of the tobacco rod (horizontally positioned), only one side shown in Figure 2 needs to be measured and any effect of gravity is ignored. After lighting, the cigarette is allowed to smoulder until its paper burn line reaches $32 \mathrm{~mm}$ from the lighting end, which is approximately the middle of the tobacco rod (58 mm long). A single-port smoking machine (AIOFM, Anhui, China), connected to the holder, provides the required smoking parameters. Temperature data can be recorded at 10 to $50 \mathrm{~Hz}$ per thermocouple.

\section{Data treatment and graphic representation}

The output from the thermocouples are stored as a function of time and location. Multiple measurements from one location are made and averaged, and then used for reconstructing temperature contour maps. To obtain temperature 


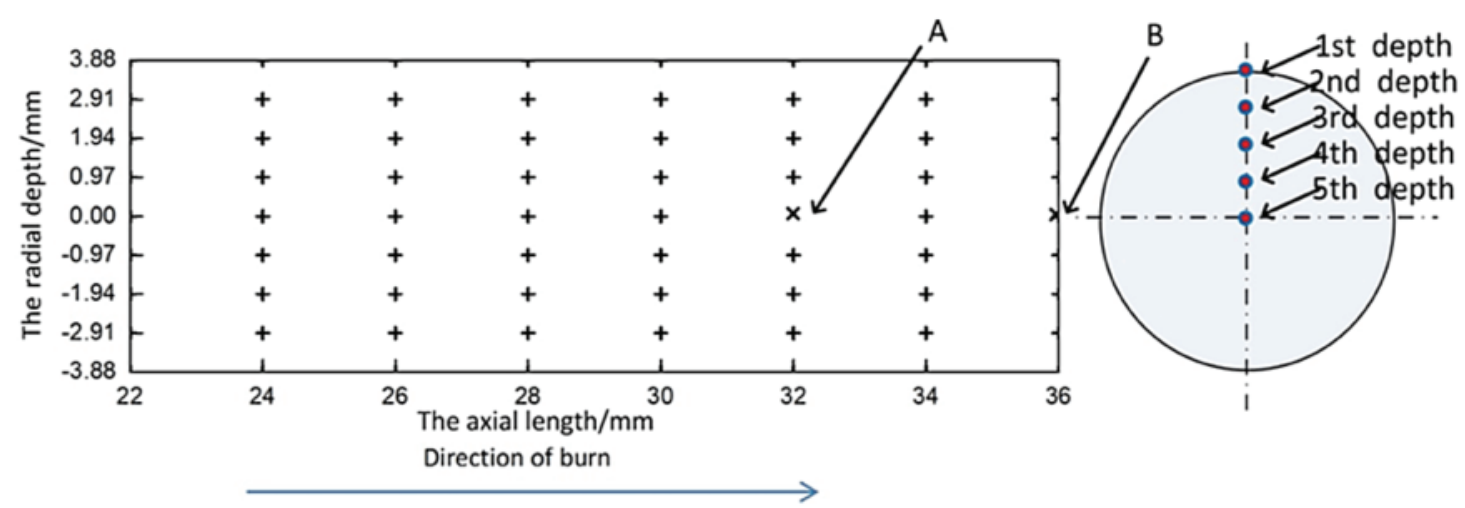

Figure 2. The thermocouple position grids along the rod and inside its cross-section.
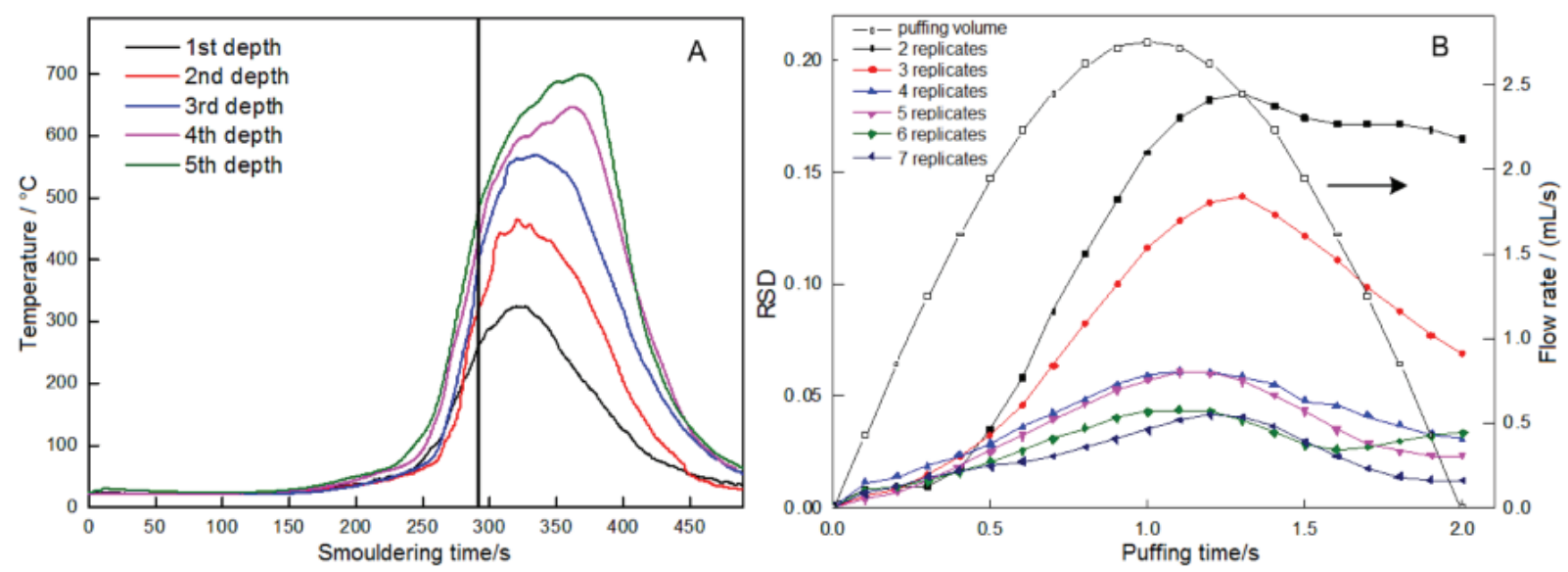

Figure 3. An example of the thermocouple outputs at different depths within the tobacco rod during static burn (A) and the relative standard deviations obtained during a $2-\mathrm{s}$ duration $35-\mathrm{mL}$ puff $(\mathrm{B})$.

values between the grids, interpolation and extrapolation of temperature readings are made by using a numeric algorithm that gives the lowest statistical errors without oversmoothing. Figure 3 A displays typical thermocouple responses inside a smouldering cigarette, the magnitude of temperature depends mainly on the insertion depth shown in Figure 2. Figure $3 \mathrm{~B}$ shows that relative standard deviations (RSD) obtained from one thermocouple depend on the puff flow, a higher puff flow tends to produce a larger $\mathrm{RSD}$, possibly by causing the tip of the thermocouple to move randomly between the cut tobacco particles. By making four or more replicate measurements, the RSD values were found to be significantly reduced. All results presented in this work were therefore averaged over four measurements.

\section{Smoking parameters and cigarette sample preparation}

To cover a range of machine-smoking parameters and one key cigarette design parameter (i.e., the filter ventilation level), nine smoking experiments were performed with four puff volumes $(15,35,45$ and $55 \mathrm{~mL})$, four puff durations $(1.5,2,4$ and $6 \mathrm{~s})$ and three filter ventilation levels (at $30 \%$ with no filter ventilation blocking, at $15 \%$ with half ventilation blocking, and at $0 \%$ with total ventilation blocking) as shown in Table 1.
Table 1. The parameters investigated in this study. Under each condition, puffing temperatures were measured for a single puff from the same rod position (see Figure 2), hence the effect of puff intervals was not studied.

\begin{tabular}{c|c|c|c|c}
\hline Test & $\begin{array}{c}\text { Puff volume } \\
(\mathrm{mL})\end{array}$ & $\begin{array}{c}\text { Puff duration } \\
(\mathrm{s})\end{array}$ & $\begin{array}{c}\text { Filter } \\
\text { ventilation } \\
\text { level (\%) }\end{array}$ & $\begin{array}{c}\text { Puff interval } \\
(\mathrm{s})\end{array}$ \\
\hline 1 & 15 & 2 & $30 \%$ & n.a. \\
2 & 35 & 2 & $30 \%$ & n.a. \\
3 & 45 & 2 & $30 \%$ & n.a. \\
4 & 55 & 2 & $30 \%$ & n.a. \\
5 & 35 & 1.5 & $30 \%$ & n.a. \\
6 & 35 & 4 & $30 \%$ & n.a. \\
\hline
\end{tabular}

n.a.: not applicable

The Kentucky Reference Cigarette 3R4F was used in this study (31). Prior to smoking the cigarettes were weightselected to an average weight of $\pm 20 \mathrm{mg}$, and pressure drop-selected to an average pressure drop of $\pm 49 \mathrm{~Pa}$. All test cigarettes were conditioned at $22{ }^{\circ} \mathrm{C}$ and $60 \%$ relative humidity for at least $4 \mathrm{~h}$. 


\section{RESULTS}

\section{Coal volume - temperature distribution}

Cigarette burning temperatures are usually measured as averaged or maximum coal temperatures for convenience in the literature (8), although early results revealed a highly dynamic and uneven temperature distribution $(11,12)$. No agreement exists as to which temperature parameter is best suited to fully describe the effect caused by different smoking conditions.

For a more accurate way to define the temperature experienced by a burning coal, it is necessary to represent a burning coal as paired volume/temperature values at each tobacco rod position, and their distributions as induced by a smoking puff. In this work, we modeled the temperature distribution using a modified ROSIN-RAMMLER (R-R) distribution equation, which is widely used to characterize the mass distribution of irregularly shaped particles (e.g., coal particles) (25). The modification to the R-R distribution assumed that the burning coal is made up of volume fractions that are heated at temperatures above $200^{\circ} \mathrm{C}$. This is a reasonable assumption given that cellulosic biomass materials typically start to experience a significant weight loss above $200^{\circ} \mathrm{C}$. During puffing, the maximum temperature of the coal is given by $T_{\max }$, with its cumulative volume fraction $\left(V, \mathrm{~mm}^{3}\right)$ corresponding to a given temperature $(T)$ expressed as:

$$
V=V_{0} \times \exp \left(-\left(\frac{T-200}{T_{s}-200}\right)^{N}\right) \times\left(\frac{1}{1+\exp \left(T-T_{\max }\right)}\right)
$$

In which, $V_{0}\left(\mathrm{~mm}^{3}\right)$ is the cumulative volume above $200^{\circ} \mathrm{C}$, which may be considered as a threshold temperature above which the coal can be regarded as "burning". $N$ is the width of the temperature distribution, given by $\left(T_{0.1}-T_{0.9}\right) . T_{0.1}$ and $T_{0.9}$ are the temperature at which $V / V_{0}$ reaches $10 \%$ and $90 \%$ percentiles, respectively. Similarly, $T_{0.5}$ is a characteristic temperature when $V$ reaches $50 \%$ of the total volume.
Figure 4 illustrates the fitting of the experimental (dotted lines) and calculated (solid lines) (using Eq.[1]) coal volume distribution against the full temperature range under two typical machine-smoking conditions. The matching between the two sets of data are reasonable for the two smoking regimes (26). The general trend is that the fraction of the coal volume decreased for higher temperatures, and all volume fractions increased as the puff progressed. As puffing time progressed (from $0 \mathrm{~s}$ to $1 \mathrm{~s}$ ), the higher temperature volume fractions (from ca. $300{ }^{\circ} \mathrm{C}$ onwards) increased more significantly than the lower temperature volume fractions. With further progress in puffing time (1 s to $2 \mathrm{~s}$ ), lower temperature volume fractions increased more significantly than the higher temperature volume fractions. The remaining differences between the two smoking regimes will be described later.

\section{Effect of puff volume on coal temperature distribution}

Figure 5 displays the changes in the four main distribution parameters $\left(V_{0}, T_{0.1}-T_{0.9}, T_{0.5}\right.$ and $\left.T_{\max }\right)$ as a function of puff volume $(15,35,45,55 \mathrm{~mL})$. For each parameter, the experimental results are shown in a 10-s time window covering the $2 \mathrm{~s}$ before the puff, the 2-s puff and also $6 \mathrm{~s}$ after the puff. The results for the total volume of the burning coal $\left(V_{0}\right)$, i.e., any volume that is heated above $200{ }^{\circ} \mathrm{C}$, is given in Figure 5 A. Each 2-s puff induced a near-linear increase in $V_{0}$ up to the end of the 2-s duration. There may be a small inflection at about $1 \mathrm{~s}$, corresponding to the peak puff flow. The increase stopped almost immediately at the end of the puff. The $15-\mathrm{mL}$ puff caused a slight decrease in $V_{0}$ at the beginning of the puff before a noticeable $V_{0}$ increase. The puffing at 35,45 and $55 \mathrm{~mL}$ caused a much quicker increase in $V_{0}$ than that of $15-\mathrm{mL}$ puff, but there were only small differences between them. The $V_{0}$ peak at the end of the 2-s puff was the highest for the 55-mL puff. For the remaining 6-s puffs, there was a gentle increase for the $15-\mathrm{mL}$ puff but a slight decrease for the $55-\mathrm{mL}$ puff.
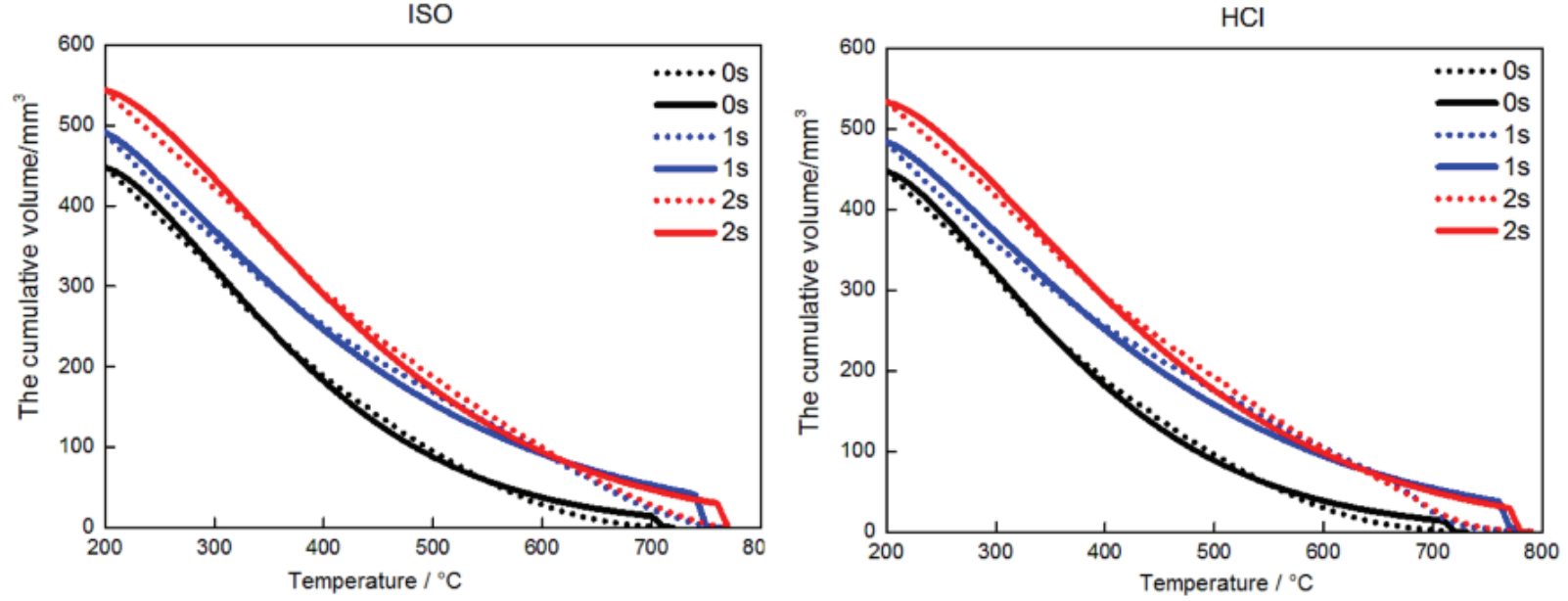

Figure 4. Cumulative coal volume at $0 \mathrm{~s}$ before puffing, and $1 \mathrm{~s}$ and $2 \mathrm{~s}$ into a puff. A: under ISO puffing parameters (35-mL puff, 2-s duration, 30\% filter ventilation), and B: under Health Canada intensive puffing parameters (55-mL puff, 2 -s duration and $0 \%$ filter ventilation). Dotted line: experimental results; solid line: calculated results. 

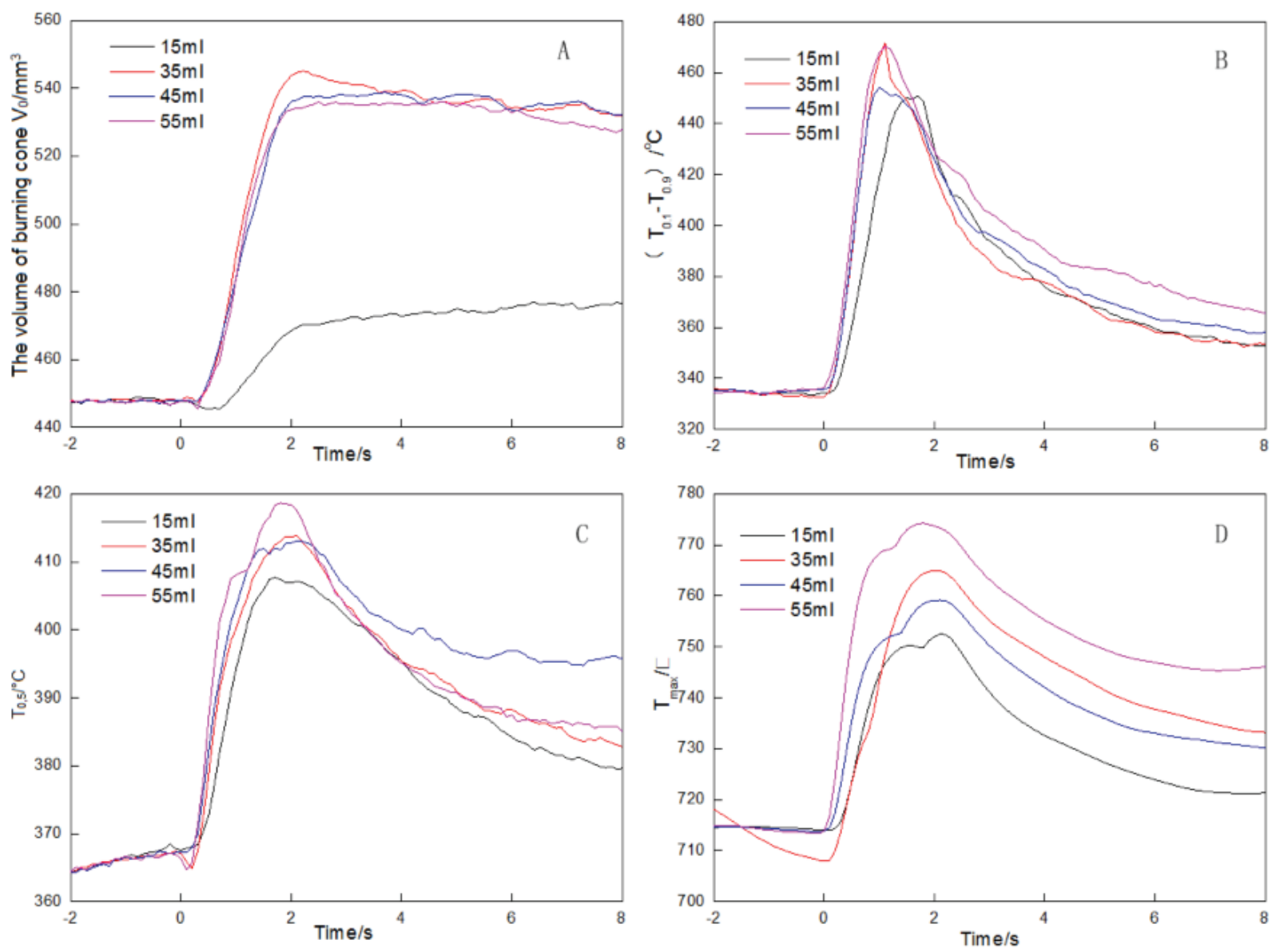

Figure 5. Variation of distribution parameters as a function of four puff volumes. Puff duration: $2 \mathrm{~s}$.

For the width of the temperature distribution (Figures $5 \mathrm{~B}$ and $5 \mathrm{C})$, characterised by $\left(T_{0.1}-T_{0.9}\right)$ and $T_{0.5}$, the overall trend was similar, although it took a little longer for the $15-\mathrm{mL}$ puff to reach its peak and the peak level was also somewhat lower than the other three puff volumes. In Figure $5 \mathrm{D}$, the maximum coal temperature under the four puffing volumes displayed a clearer separation, indicating this parameter is more sensitive to the puff volume changes, probably because it is a single temperature reading from a single location. Each puff volume increase appeared to produce an approximate 10-degree increase in the maximum temperature. In Table 2 the coal volume is divided into

Table 2. Changes in burn volume fraction under different puff volumes. The burn volume was divided into three temperature ranges: lowtemperature volume (LTV): $200-400{ }^{\circ} \mathrm{C}$, medium-temperature volume (MTV): $400-600{ }^{\circ} \mathrm{C}$, and high-temperature volume (HTV): $>600{ }^{\circ} \mathrm{C}$. Both coal volume $\left(\mathrm{mm}^{3}\right)$ and percentages of coal volume change relative to $0 \mathrm{~s}$ (within bracket) are given.

\begin{tabular}{|c|c|c|c|c|c|c|c|c|}
\hline \multirow{3}{*}{ Puff volume } & \multirow{3}{*}{ Temperature range } & \multicolumn{7}{|c|}{ Coal volume $\mathrm{mm}^{3}$ ( $\%$ of coal volume change) } \\
\hline & & \multicolumn{7}{|c|}{ Time from the start of puff (s) } \\
\hline & & 0 & & 1 & & 2 & & 6 \\
\hline \multirow{3}{*}{$15 \mathrm{~mL}$} & $\mathrm{LTV} / \mathrm{mm}^{3}$ & 258.5 & 225.5 & $(-12.8 \%)$ & 220.2 & $(-14.8 \%)$ & 249.6 & $(-3.4 \%)$ \\
\hline & $\mathrm{MTV} / \mathrm{mm}^{3}$ & 160.2 & 157.8 & $(-1.5 \%)$ & 166.5 & $(3.9 \%)$ & 184.5 & $(15.2 \%)$ \\
\hline & $\mathrm{HTV} / \mathrm{mm}^{3}$ & 29.3 & 66.9 & $(128.3 \%)$ & 81.9 & $(179.5 \%)$ & 41.3 & $(41.0 \%)$ \\
\hline \multirow{3}{*}{$35 \mathrm{~mL}$} & $\mathrm{LTV} / \mathrm{mm}^{3}$ & 260.2 & 240.1 & $(-7.7 \%)$ & 253.1 & $(-2.7 \%)$ & 279.7 & $(7.5 \%)$ \\
\hline & $\mathrm{MTV} / \mathrm{mm}^{3}$ & 159.2 & 158.4 & $(-0.5 \%)$ & 191.0 & $(20.0 \%)$ & 199.9 & (25.6\%) \\
\hline & $\mathrm{HTV} / \mathrm{mm}^{3}$ & 28.5 & 92.9 & $(226.0 \%)$ & 99.6 & $(249.5 \%)$ & 54.5 & $(91.2 \%)$ \\
\hline \multirow{3}{*}{$45 \mathrm{~mL}$} & $\mathrm{LTV} / \mathrm{mm}^{3}$ & 260.0 & 231.2 & $(-11.1 \%)$ & 246.0 & $(-5.4 \%)$ & 263.8 & $(1.5 \%)$ \\
\hline & $\mathrm{MTV} / \mathrm{mm}^{3}$ & 158.2 & 162.6 & $(2.8 \%)$ & 190.9 & $(20.7 \%)$ & 208.5 & (31.8\%) \\
\hline & $\mathrm{HTV} / \mathrm{mm}^{3}$ & 29.6 & 90.5 & $(205.7 \%)$ & 99.2 & $(235.1 \%)$ & 61.4 & $(107.4 \%)$ \\
\hline \multirow{3}{*}{$55 \mathrm{~mL}$} & LTV $/ \mathrm{mm}^{3}$ & 260.7 & 229.5 & $(-12.0 \%)$ & 242.1 & $(-7.1 \%)$ & 283.5 & $(8.7 \%)$ \\
\hline & $\mathrm{MTV} / \mathrm{mm}^{3}$ & 157.0 & 150.1 & $(-4.4 \%)$ & 188.1 & $(19.8 \%)$ & 184.6 & $(17.6 \%)$ \\
\hline & $\mathrm{HTV} / \mathrm{mm}^{3}$ & 30.0 & 105.0 & $(250.0 \%)$ & 103.5 & $(245.0 \%)$ & 64.6 & $(115.3 \%)$ \\
\hline
\end{tabular}


three temperature ranges, a low-temperature range (LTV) (200 to $400{ }^{\circ} \mathrm{C}$ ), a medium temperature range (MTV) $(400$ to $600{ }^{\circ} \mathrm{C}$ ), and a high temperature range (HTV) $\left(>600{ }^{\circ} \mathrm{C}\right)$. Their values (in $\left.\mathrm{mm}^{3}\right)$ as a function of the time from the start of the puff were tabulated, together with the percentage of the volume change from the start of the puffing $(\mathrm{t}=0 \mathrm{~s})$. At $\mathrm{t}=0 \mathrm{~s}$, the size of the coal volume was always in the order of: LTV $>$ MTV $>$ HTV. Throughout the puff ( 0 to $2 \mathrm{~s}$ ) and then the extended period ( 2 to $6 \mathrm{~s}$ ), the LTV first shrank and then recovered or expanded in proportion to the increase in puff volume. The initial dipping for the MTV was much less around the $1 \mathrm{~s}$ than the LTV and always ended up significantly bigger than at the start of the puff. For the HTV, its volume increased much more substantially during the puff and decreased rapidly after the puff. The increase peaked around $2 \mathrm{~s}$ and then decreased at $6 \mathrm{~s}$. The detailed examination in different coal volume fractions complemented the trend shown in Figure 5 A for the total coal volume.

Figure 6 displays two examples of temperature responses at particular locations within the burning coal. For Point A (Figure 1), the thermocouple was at the paper burn line position and its temperature profile matched approximately the bell-shaped puff flow, with the peak temperature occurring around the 2-s mark, and moving slightly to earlier times with increasing puff volume (Figure 6). For Point B (cf. Figure 1), the thermocouple was $4 \mathrm{~mm}$ downstream from Point A, each puff produced a significantly smaller temperature increase as compared to Point A. Its temperature continued to increase post puffing, most likely due to the burning coal moving closer to the measurement location.

Figure 7 illustrates the temperature (left) and temperature gradient (right) contour maps under the four puffing volumes, corresponding to the middle of the 2-s puff where the puff flow was the highest. The red vertical line gives the approximate position of the paper burn line for each case. For the temperature contour maps, the clearest differences could be seen in the central region of the coal where the highest gas-phase temperature were: the 2-D view of the region increased in size and extended further into the air flow direction (to the right hand side of the diagram). The corresponding temperature gradient maps showed the effects of the four puffing volumes much more clearly. Two regions of high temperature gradients developed when the puff volume increased from $15 \mathrm{~mL}$ to $35 \mathrm{~mL}$. With further increase in puff volume $(35,45$ and $55 \mathrm{~mL})$, the outer contour lines became less smooth, possibly indicative of more turbulent thermal mass and flow transfer. The high temperature region became enlarged with the 55-mL puff and shifted towards the right-hand direction. The degree of variation for the temperature gradients may be linked to the extent of thermal oxidation, and therefore associated with the magnitude and position of the air influx. Under each puffing volume, comparing the higher temperature region on the left against the greater temperature gradient region on the right reveals that they clearly did not occur at the same location. The results in Figure 7 are similar to some early studies $(11,12)$, which highlighted the highly dynamic and inhomogeneous nature of the thermal behaviour of the burning coal during puffing.

\section{Effect of puff duration on coal temperature distribution}

For a fixed 35-mL puff, Figure 8 displays the distribution parameters as a function of puff durations: 1.5, 2.0, 4.0 and $6.0 \mathrm{~s}$. In Figure 8 (A), the main influence of the extended puff duration on the coal volume was on the speed with which the volume started to expand. With the 1.5-s puff duration, the volume increased almost instantly from the start of the puff, whilst the coal volume did not increase after ca. $1.0 \mathrm{~s}$ into the puff and the expansion continued beyond the puff and lasted until ca. $4.0 \mathrm{~s}$ from the start of the puff. In all the cases shown, the volume increase continued beyond the end of the puff duration, indicating that enough energy was produced during the puff to sustain coal volume (Figure 8). Figure $8 \mathrm{~B}$ to $\mathrm{D}$ show the two temperature-related distribution parameters plus the peak temperature; these are better separated under the four puff durations than those under the different puff volumes (Figure 5). The longer duration generally had the effect of delaying the onset of the maximum and producing a slower decay.
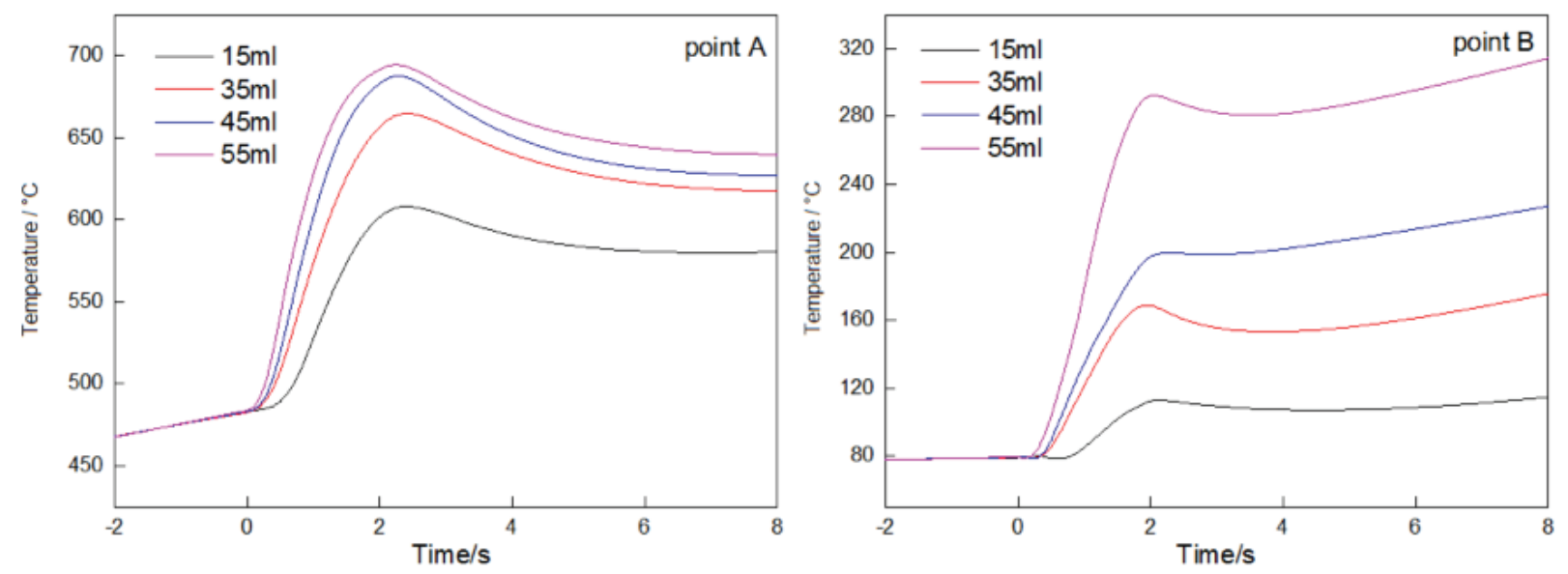

Figure 6. Temperature variation at two locations along the central axis (see Figure 1). 


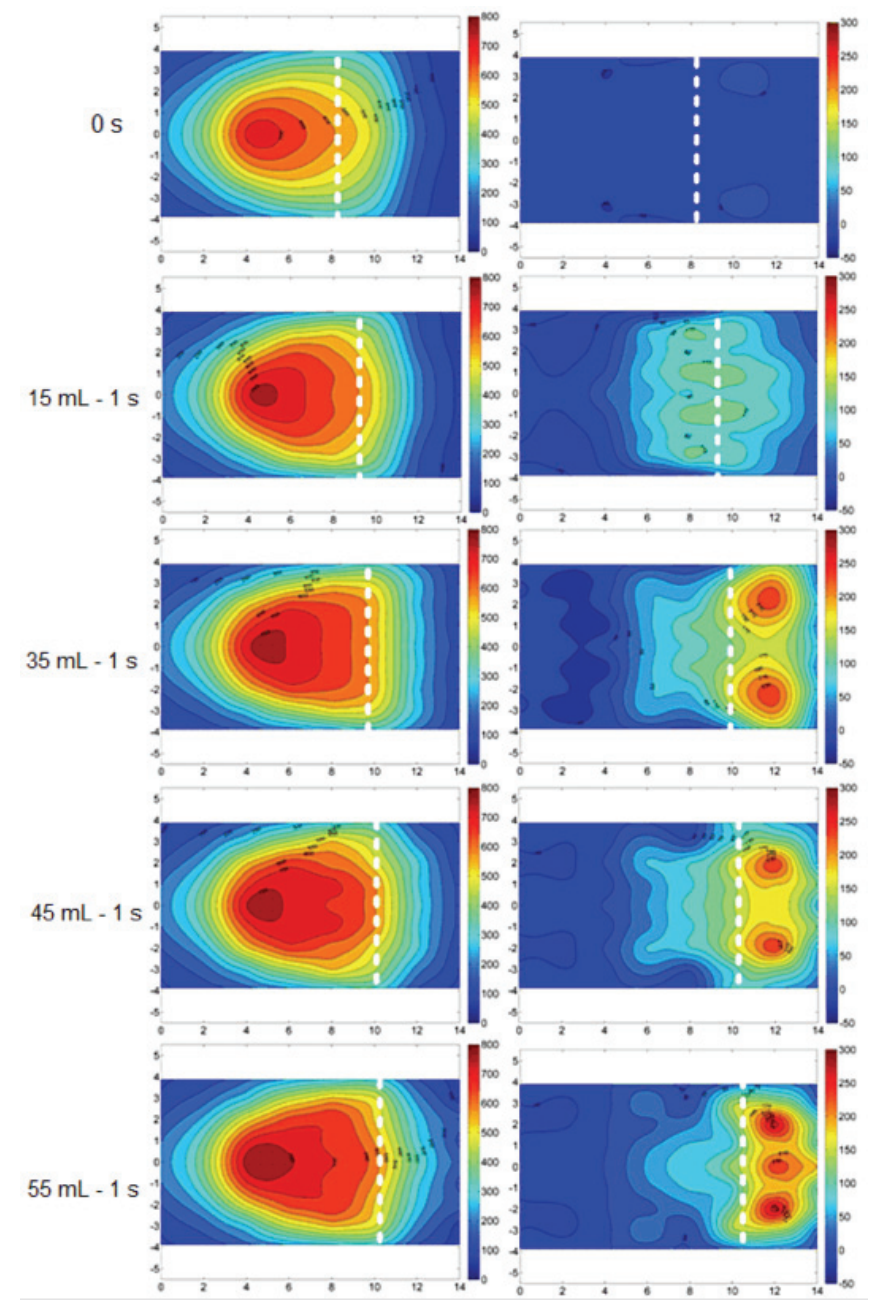

Figure 7. Temperature $\mathrm{T}\left({ }^{\circ} \mathrm{C}\right.$, left) and temperature gradient $\mathrm{dT} / \mathrm{dt}\left({ }^{\circ} \mathrm{C} / \mathrm{s}\right.$, right) contours at $1 \mathrm{~s}$ into the 2 -s puff as a function of puff volume.

For the coal volumes distributed within the three temperature ranges (LTV, MTV and HTV), Table 3 shows that the LTV was relatively independent of the variation in the puff durations. MTV appeared to be increased when the puff duration was at $6.0 \mathrm{~s}$, as compared to the other three puff duration studied. For the HTV, this had the opposite effect of decreasing its size as the puff duration lasted $6.0 \mathrm{~s}$. Although the overall trend within each volume fraction is similar to that listed in Table 2, the final volumes for the LVT fraction was larger in Table 3.

Figure 9 shows that having the same volume of air drawn over increasing time affected the inner gas-phase temperatures: the inner higher temperature regions for the 4.0 and 6.0 -s puff duration were visibly larger and extended to the right (or downstream) direction. Reflected in the temperature gradient map, the 1.5-s puff duration appeared to have caused more intense temperature rise, close to the paper burn line. Extending the puff duration had the effect of reducing and smoothing the temperature gradient maps significantly. In each case, the high temperature gradient region were all distributed downstream from the paper burn line position. It appears that the position of the paper burn line was moved further to the right with the extended puff duration.
Effect of filter ventilation blocking on coal temperature distribution

Filter ventilation has been one of the main cigarette design tools used to control mainstream smoke yields under machine-smoking conditions $(1,27)$. Its main role is to reduce the amount of air passing through the tobacco rod (16), hence, it has similar effects on the cigarette combustion e.g., varying the puff volumes. For the $3 \mathrm{R} 4 \mathrm{~F}$ cigarettes tested in this work, those cigarettes have ca. $30 \%$ level of ventilation. Two other ventilation levels were also studied: $15 \%$ (half of the ventilation was blocked) and $0 \%$ (all the ventilation was blocked). As Figure 10 shows, reducing the level of ventilation caused a faster rise in the hot coal volume and a higher value for the coal volume under the $100 \%$ ventilation blocking (Figure $10 \mathrm{~A}$ ). For the two characteristic temperature parameters (Figure $10 \mathrm{~B}$ and $10 \mathrm{C}$ ), the increased filter ventilation blocking clearly increased the peak temperature values. The effect on the maximum temperature was more mixed (Figure $10 \mathrm{D}$ ).

In response to the increase in the puff volume or increased ventilation blocking, Table 4 shows similar trends for the LTV, MTV and HTV regions as those given in Table 2. Temperature and temperature gradient maps also followed a similar trend with increasing puff volume (Figure 7). The reason for this similarity and the magnitude of the differences was determined by the amount of air flow into the coal itself rather than the total puff volume. Hence, the order of the puffing intensity studied in this work for a 2-s puff duration (Table 1) was: $55 \mathrm{~mL}$ with $30 \%$ ventilation $(=38.5 \mathrm{~mL})>35 \mathrm{~mL}$ puff with $100 \%$ ventilation blocking $>45 \mathrm{~mL}$ with $30 \%$ ventilation $(=31.5 \mathrm{~mL})>35 \mathrm{~mL}$ with $30 \%$ ventilation $(=24.5 \mathrm{~mL})$. The results in Table 4 and Table 2 followed this trend reasonably consistently.

\section{DISCUSSION}

A single temperature or multiple temperature profiles have been used to define a burning cigarette when the effects of smoking intensity are discussed in the literature (9). Sometimes this is necessary, e.g., to deduce a set of temperature parameters that can be used for pyrolysis experiments $(28,29)$. The results shown in this work demonstrate that cigarette combustion behaviour as reflected by gas-phase temperatures is too complex to be accurately represented by this approach. Any investigation into possible links between thermophysics and smoke chemistry under different smoking intensities should examine this relationship with a more complete picture in mind. BAKER's early temperature (both solid and gas-phase) measurements already show that cigarette coal temperatures display complex distributions and variations, and are best described by temperature contours as a function of puffing time or locations along the cigarette $(11,12)$.

In this work, we have evaluated a number of approaches to characterize cigarette burning temperatures, all from the coal volume-temperature distribution perspective. The results presented here show that these approaches are a better way to examine the cigarette combustion phenomenon. 

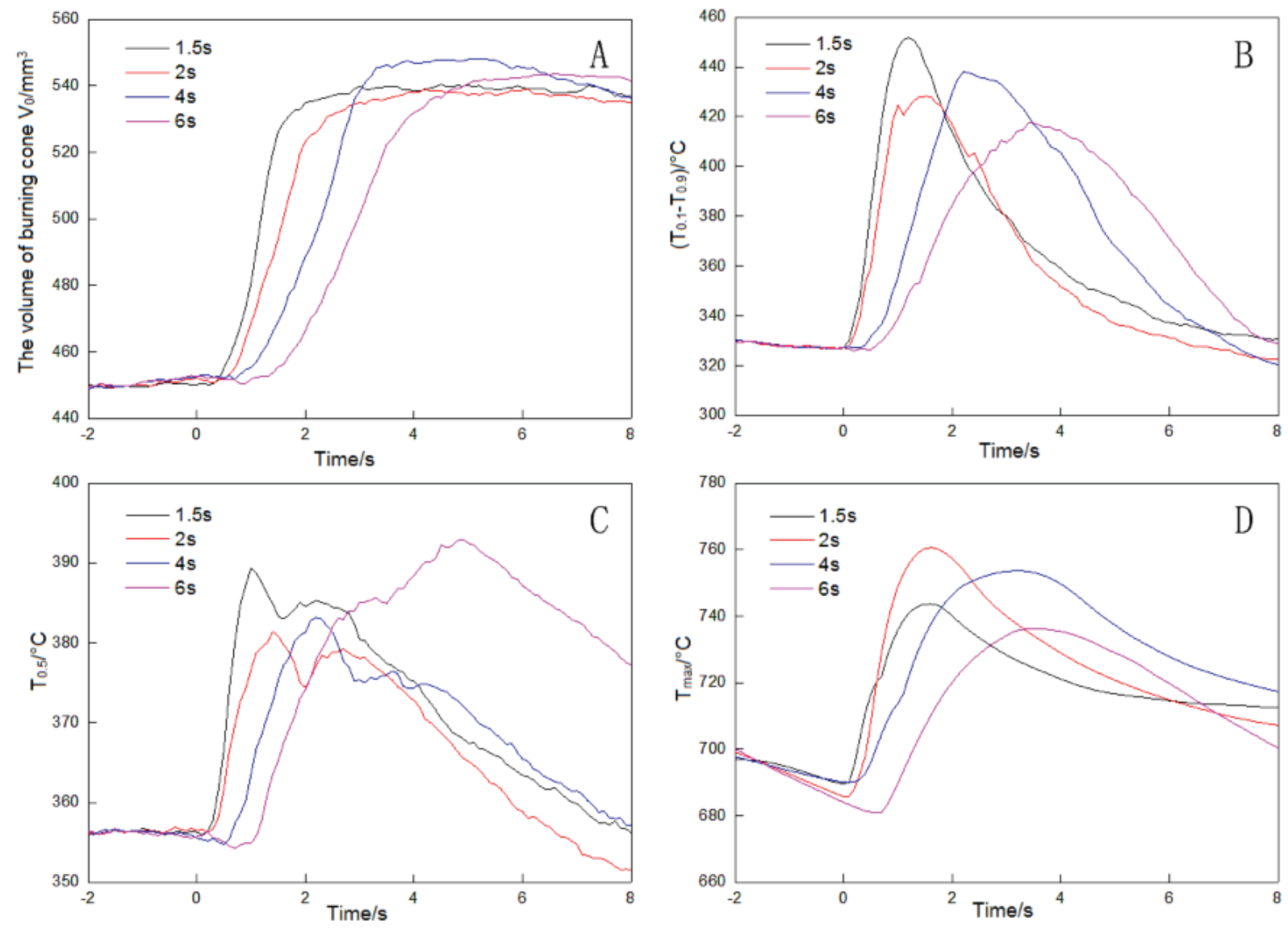

Figure 8. Variation of distribution parameters as a function of puffing duration. Puff volume: $35 \mathrm{~mL}$.

Table 3. Changes in burn volumes under four puff durations. The burn volume was divided into three temperature ranges: low-temperature volume (LTV): $200-400^{\circ} \mathrm{C}$, medium-temperature volume (MTV): $400-600^{\circ} \mathrm{C}$, and high-temperature volume (HTV): $>600{ }^{\circ} \mathrm{C}$. Both absolute volumes $\left(\mathrm{mm}^{3}\right)$ and percentages of volume change relative to $0 \mathrm{~s}$ (within bracket) are given.

\begin{tabular}{|c|c|c|c|c|c|c|c|c|}
\hline \multirow{3}{*}{ Puff volume } & \multirow{3}{*}{ Temperature range } & \multicolumn{7}{|c|}{ Burn volume ( $\%$ of burn volume change) } \\
\hline & & \multicolumn{7}{|c|}{ Time from the start of puff (s) } \\
\hline & & 0 & & 1 & & 2 & & 6 \\
\hline $1.5 \mathrm{~s}$ & $\begin{array}{l}\text { LTV } / \mathrm{mm}^{3} \\
\text { MTV } / \mathrm{mm}^{3} \\
\mathrm{HTV} / \mathrm{mm}^{3}\end{array}$ & $\begin{array}{r}272.3 \\
155.8 \\
20.8\end{array}$ & $\begin{array}{r}247.8 \\
146.9 \\
68.6\end{array}$ & $\begin{array}{r}(-9.5 \%) \\
(-5.7 \%) \\
(230.8 \%)\end{array}$ & $\begin{array}{r}276.9 \\
162.8 \\
86.6\end{array}$ & $\begin{array}{r}(1.2 \%) \\
(4.5 \%) \\
(316.3 \%)\end{array}$ & $\begin{array}{r}315.5 \\
184.1 \\
39.4\end{array}$ & $\begin{array}{l}(15.3 \%) \\
(18.2 \%) \\
(89.4 \%)\end{array}$ \\
\hline $2.0 \mathrm{~s}$ & $\begin{array}{l}\mathrm{LTV} / \mathrm{mm}^{3} \\
\mathrm{MTV} / \mathrm{mm}^{3} \\
\mathrm{HTV} / \mathrm{mm}^{3}\end{array}$ & $\begin{array}{r}273.8 \\
157.5 \\
20.9\end{array}$ & $\begin{array}{r}255.2 \\
141.1 \\
72.2\end{array}$ & $\begin{array}{r}(-6.8 \%) \\
(-10.4 \%) \\
(245.5 \%)\end{array}$ & $\begin{array}{r}288.0 \\
155.7 \\
79.7\end{array}$ & $\begin{array}{r}(5.2 \%) \\
(-1.1 \%) \\
(281.3 \%)\end{array}$ & $\begin{array}{r}334.5 \\
165.5 \\
38.7\end{array}$ & $\begin{array}{r}(22.2 \%) \\
(5.1 \%) \\
(85.2 \%)\end{array}$ \\
\hline $4.0 \mathrm{~s}$ & $\begin{array}{l}\text { LTV } / \mathrm{mm}^{3} \\
\text { MTV } / \mathrm{mm}^{3} \\
\mathrm{HTV} / \mathrm{mm}^{3}\end{array}$ & $\begin{array}{r}275.1 \\
157.1 \\
20.5\end{array}$ & $\begin{array}{r}261.4 \\
152.2 \\
75.0\end{array}$ & $\begin{array}{r}(-5.0 \%) \\
(-3.1 \%) \\
(265.9 \%)\end{array}$ & $\begin{array}{r}306.2 \\
165.5 \\
75.2\end{array}$ & $\begin{array}{r}(11.3 \%) \\
(5.3 \%) \\
(266.8 \%)\end{array}$ & $\begin{array}{r}341.2 \\
159.5 \\
35.7\end{array}$ & $\begin{array}{r}(24.0 \%) \\
(1.5 \%) \\
(74.1 \%)\end{array}$ \\
\hline $6.0 \mathrm{~s}$ & $\begin{array}{l}\text { LTV / } \mathrm{mm}^{3} \\
\text { MTV / } \mathrm{mm}^{3} \\
\mathrm{HTV} / \mathrm{mm}^{3}\end{array}$ & $\begin{array}{r}274.3 \\
157.6 \\
20.6\end{array}$ & $\begin{array}{r}261.4 \\
171.6 \\
68.2\end{array}$ & $\begin{array}{r}(-4.7 \%) \\
(8.9 \%) \\
(231.1 \%)\end{array}$ & $\begin{array}{r}287.7 \\
191.1 \\
63.9\end{array}$ & $\begin{array}{r}(4.9 \%) \\
(21.3 \%) \\
(210.2 \%)\end{array}$ & $\begin{array}{r}322.1 \\
178.3 \\
37.2\end{array}$ & $\begin{array}{l}(17.4 \%) \\
(13.1 \%) \\
(58.7 \%)\end{array}$ \\
\hline
\end{tabular}

The first approach, as shown in Figure 4, is an overview of cigarette coal volume-temperature distribution as a function of puffing time. Such data on experimentally determined and mathematically modelled coal volume-temperature distributions over the two standard machine-smoking protocols are powerful in highlighting the relative changes in coal volume and their associated gas-phase temperature. It gave a useful overview of the burning coal as its different volume fractions expand or contract through a 2-s puff: the lower to medium temperature volume fractions experienced a more significant volume increase as the puff progressed. One drawback of the results in Figure 4 is that it depicts less mechanistic information as compared to a temperature map. 


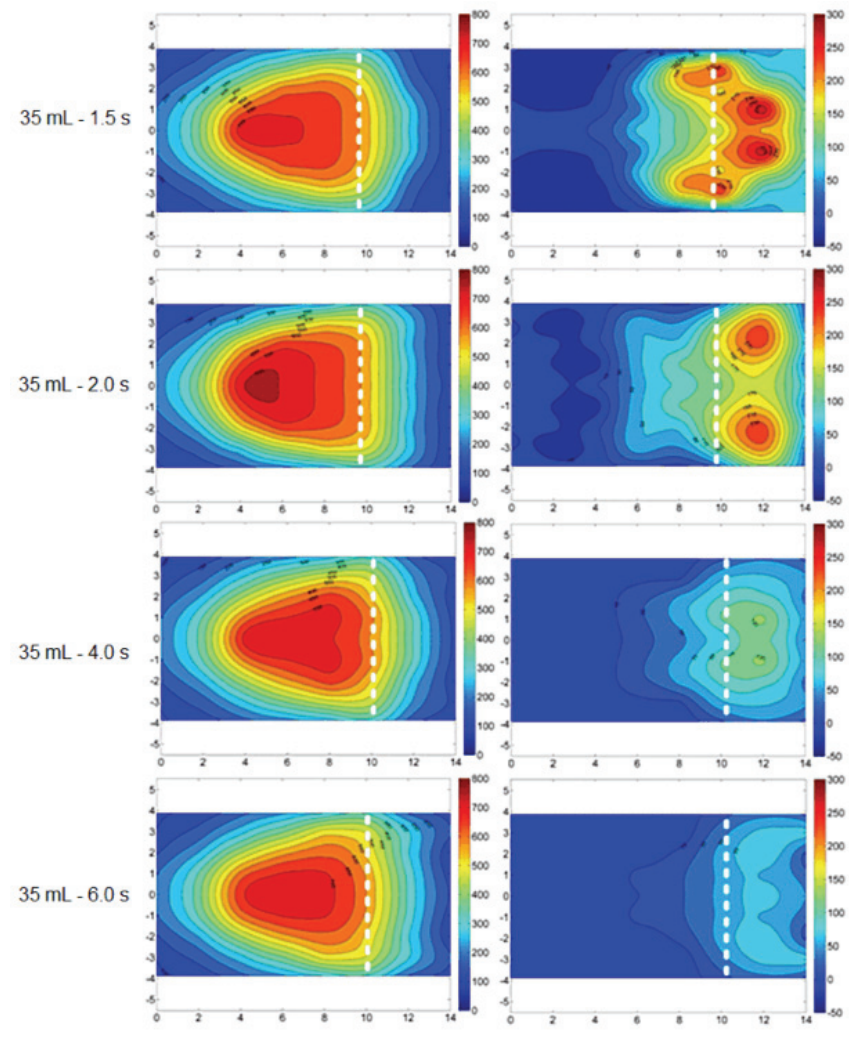

Figure 9. Temperature $\mathrm{T}\left({ }^{\circ} \mathrm{C}\right.$, left) and temperature gradient $\mathrm{dT} / \mathrm{dt}\left({ }^{\circ} \mathrm{C} / \mathrm{s}\right.$, right) contours as a function of puff duration. Puff volume: $35 \mathrm{~mL}$. Capture time: $0.75 \mathrm{~s}, 1.0 \mathrm{~s}, 2.0 \mathrm{~s}, 3.0 \mathrm{~s}$.
Another approach, which provided a more detailed examination of the effects of the smoking parameters was to plot the mathematically defined distribution parameters as a function of the puffing time, as shown in Figure 5. This revealed directly that some of the distribution parameters were useful to extract mechanistic details, e.g., the separation in $V_{o}$ between $15 \mathrm{~mL}$ and $35 \mathrm{~mL}$ puff was distinctive, much more so than either the $\left(T_{0.1}-T_{0.9}\right)$ or $T_{0.5}$ distribution parameters. The peak puff temperature $\left(T_{\max }\right)$ was more sensitive than the distributed temperatures. In other words, putting the information together, the burning coal under the range of puffing volumes appeared to be expanded significantly with a higher maximum temperature but the relative distributions of the different volume did not change significantly.

Tabulating the coal volume fractions into three temperature ranges (LTV, MTV and HTV) and examining their relative changes as a function of puffing time also provided useful insights into the thermophysical behaviour of the burning coal. Prior to puffing (i.e., during steady-state smouldering), the LTV predominantly occupied the peripheral surface layer of the coal (Figure 7), which thermally shielded the inner MTV and HTV from radiative heat losses. Upon puffing, incoming air was firstly drawn through the LTV and thus cooled its temperature as a result the lower temperatures of the LTV region were unable to utilise the oxygen supplied for oxidative combustion. This was shown as an initial thermal lag that lasted up to $6 \mathrm{~s}$ after the start of the puff (Tables 2, 3 and 4).
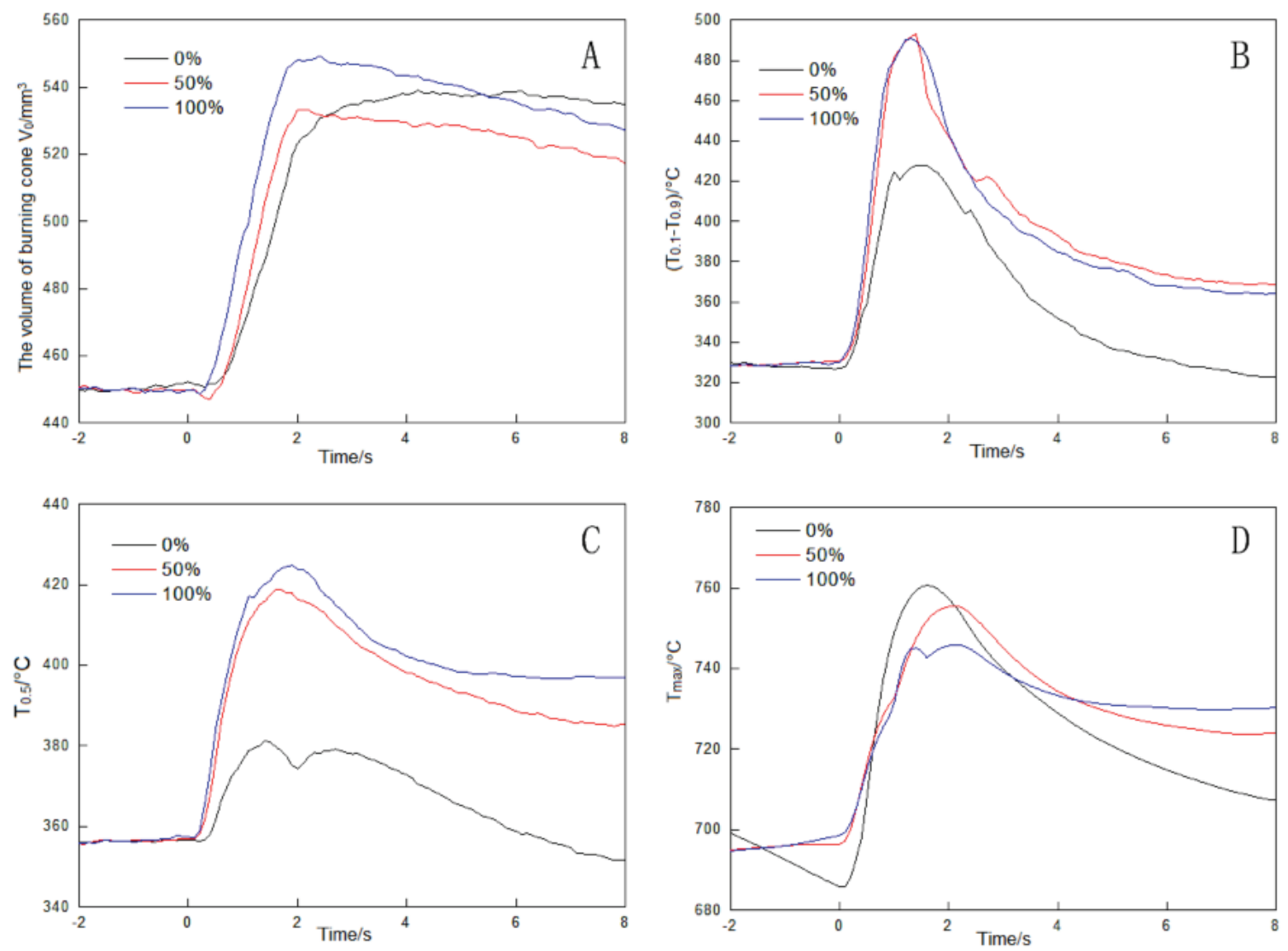

Figure 10. Variation of distribution parameters as a function of filter ventilation blocking level. Puff volume: $35 \mathrm{~mL}$. 
Table 4. Changes in burn volume fractions under different ventilation blocking levels. The burn volume was divided into three temperature ranges: low-temperature volume (LTV): $200-400{ }^{\circ} \mathrm{C}$, medium-temperature volume (MTV): $400-600{ }^{\circ} \mathrm{C}$, and high-temperature volume (HTV): $>600^{\circ} \mathrm{C}$. Both absolute volumes $\left(\mathrm{mm}^{3}\right)$ and percentages of volume change relative to $0 \mathrm{~s}$ (within bracket) are given.

\begin{tabular}{|c|c|c|c|c|c|c|c|c|}
\hline \multirow{3}{*}{ Puff volume } & \multirow{3}{*}{ Temperature range } & \multicolumn{7}{|c|}{ Ventilation volume ( $\%$ of ventilation volume change) } \\
\hline & & \multicolumn{7}{|c|}{ Time from the start of puff (s) } \\
\hline & & 0 & & 1 & & 2 & & 6 \\
\hline $0 \%$ & $\begin{array}{l}\mathrm{LTV} / \mathrm{mm}^{3} \\
\mathrm{MTV} / \mathrm{mm}^{3} \\
\mathrm{HTV} / \mathrm{mm}^{3}\end{array}$ & $\begin{array}{r}273.8 \\
157.5 \\
20.9\end{array}$ & $\begin{array}{r}255.2 \\
141.3 \\
72.2\end{array}$ & $\begin{array}{r}(-6.8 \%) \\
(-10.3 \%) \\
(245.5 \%)\end{array}$ & $\begin{array}{c}288.0 \\
155.7 \\
79.72\end{array}$ & $\begin{array}{r}(5.2 \%) \\
(-1.1 \%) \\
(281.4 \%)\end{array}$ & $\begin{array}{r}334.5 \\
165.5 \\
38.7\end{array}$ & $\begin{array}{r}(22.2 \%) \\
(5.1 \%) \\
(85.2 \%)\end{array}$ \\
\hline $50 \%$ & $\begin{array}{l}\text { LTV / } \mathrm{mm}^{3} \\
\text { MTV / } \mathrm{mm}^{3} \\
\text { HTV } / \mathrm{mm}^{3}\end{array}$ & $\begin{array}{r}271.5 \\
155.1 \\
22.9\end{array}$ & $\begin{array}{l}225.3 \\
147.5 \\
102.8\end{array}$ & $\begin{array}{r}(-17.0 \%) \\
(-4.9 \%) \\
348.9 \%)\end{array}$ & $\begin{array}{l}244.3 \\
181.0 \\
107.9\end{array}$ & $\begin{array}{r}(-10.0 \%) \\
(16.7 \%) \\
(371.2 \%)\end{array}$ & $\begin{array}{r}271.9 \\
196.6 \\
56.7\end{array}$ & $\begin{array}{r}(0.1 \%) \\
(26.8 \%) \\
(147.6 \%)\end{array}$ \\
\hline $100 \%$ & $\begin{array}{l}\text { LTV / } \mathrm{mm}^{3} \\
\text { MTV / } \mathrm{mm}^{3} \\
\text { HTV } / \mathrm{mm}^{3}\end{array}$ & $\begin{array}{r}271.3 \\
156.1 \\
22.4\end{array}$ & $\begin{array}{l}228.9 \\
156.5 \\
110.5\end{array}$ & $\begin{array}{r}(-15.6 \%) \\
(0.3 \%) \\
(393.2 \%)\end{array}$ & $\begin{array}{l}241.0 \\
196.5 \\
110.7\end{array}$ & $\begin{array}{r}(-11.2 \%) \\
(25.9 \%) \\
(394.2 \%)\end{array}$ & $\begin{array}{r}268.4 \\
202.1 \\
65.1\end{array}$ & $\begin{array}{r}(-1.1 \%) \\
(29.5 \%) \\
(190.6 \%)\end{array}$ \\
\hline
\end{tabular}

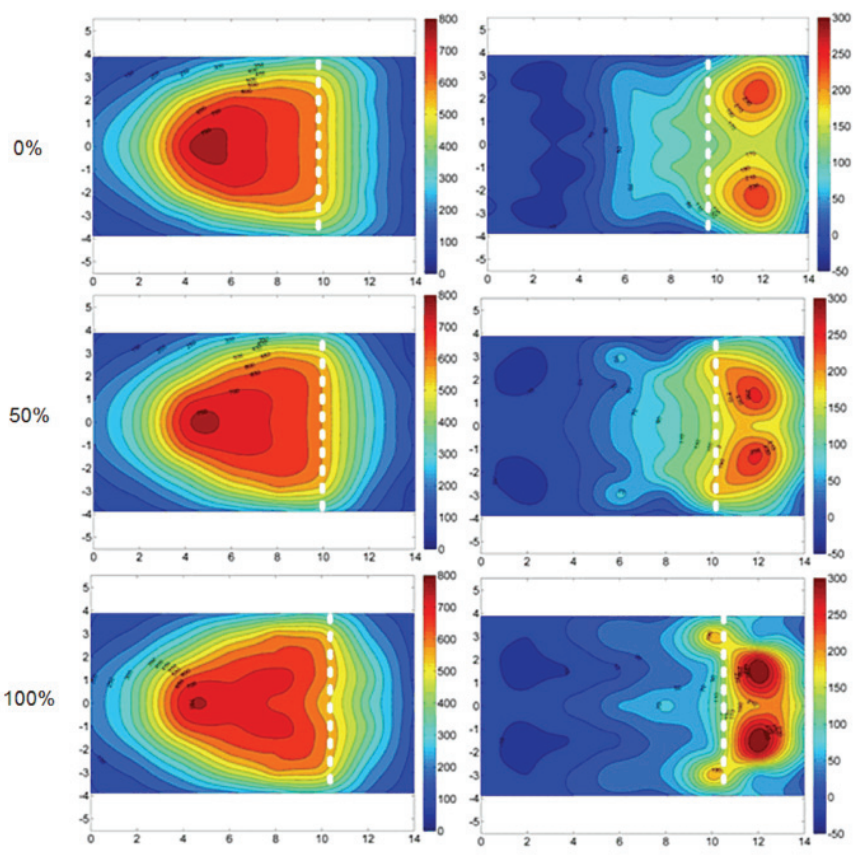

Figure 11. Temperature $\mathrm{T}\left({ }^{\circ} \mathrm{C}\right.$, left) and temperature gradient $\mathrm{dT} / \mathrm{dt}\left({ }^{\circ} \mathrm{C} / \mathrm{s}\right.$, right) contours as a function of filter ventilation levels. Puff volume: $35 \mathrm{~mL}$, puff duration: $2 \mathrm{~s}$, capture time: $1 \mathrm{~s}$.

As air entered the inner MTV and HTV regions of the coal, significant oxidation occurred which released enough energy to raise the temperature, almost immediately for MTV and HTV, and somewhat later for LTV. As shown in Table 2, for example, by establishing the smouldering coal volume-temperature distribution, the effects of smoking intensities and the relative changes in coal volumes at different temperature ranges could be studied in a meaningful way.

Finally, comprehensive temperature and temperature gradient contours were used to examine not only the magnitudes of the volume-temperature changes, but also the precise locations where these changes occurred as a function of smoking intensities or smoking time. The location information is important to understand any possi- ble thermophysical impact on smoke chemistry, because identical temperature changes occurring at different locations may generate quite different smoke chemistry outcomes. For example, a piece of unburnt tobacco (further downstream from the paper burn line) would generate different chemical species as opposed to a semi-charred tobacco piece when experiencing the same temperature changes. Thus spatial changes in burn volumes of similar temperature ranges could be responsible for subtle changes in smoke chemistry as observed by inserting a microsampling probe into the interior of the burning coal (30). Temperature gradient contours, on the other hand, gave supplementary information on the intensity of oxidation and could be useful to understand the thermophysics from two aspects: firstly, a higher temperature gradient may be connected to regions experiencing more of the incoming air, provided that the temperature is high enough for oxidative combustion; and secondly, a higher gradient activity often preceded a marked temperature rises.

In summary, the results shown in this work excludes the notion that effects of smoking intensity could be reflected or understood by a higher or lower cigarette combustion temperature. The real phenomenon, as indicated by gasphase temperature, is much more complicated than that, and has to be approached from a set of parameters (time, temperature, location, volume, gas flow) in a distributed manner.

There are a number of limitations in this work. For example, the results shown are only the gas-phase temperatures due to the technique used. Further development in solid-phase temperatures sensor techniques are needed to allow solidphase temperature to be measured with similar spatial and time resolution. The effect of puff interval was not studied in this work. In a previous study, gas-phase temperature from two consecutive puffs were measured to investigate the effect of puff interval $(60 \mathrm{~s})$ on the subsequent puff temperatures (24). The distribution parameters were found to take between 15 to $60 \mathrm{~s}$ to return to their baseline levels, hence shorter puff intervals were expected to influence the subsequent coal temperature. The results nevertheless demonstrate that the technique used here was sensitive enough to study these subtle thermophysical effects. 


\section{CONCLUSIONS}

An improved thermocouple technique was used in this study to examine systematically the effects of puffing intensity (puff volume and puff duration) and filter ventilation levels on gas-phase coal temperatures. The results obtained demonstrated that cigarette combustion, as reflected by gas-phase temperature, is complex and cannot adequately be described by a single temperature or temperature profile. A mathematical equation was used to fit the experimental coal volumes at different temperatures. These experimental parameters were found to be useful in providing mechanistic insights into the relative adjustments between coal volume fractions at various times under the different puffing intensities. Dividing the coal volume into fixed temperature ranges, and monitoring its change from steady-state smouldering into the dynamic processes in a puff identified the regions prone to thermal lags and rapid volume expansions. Mapping the temperature and temperature gradient changes into spatially resolved contours further revealed the regions of air influx and high oxidative reactions. The results have direct implications for studies aimed at understanding smoke chemistry production and pyrolysis behaviours of cigarette ingredients.

\section{REFERENCES}

1. Hoffmann, D. and I. Hoffmann: The Changing Cigarette: Chemical Studies and Bioassays, Risks Associated with Smoking Cigarettes with Low MachineMeasured Yields of Tar; US Department of Health and Human Services, National Institutes of Health, National Cancer Institute, Bethesda, MD, USA (2001) pp. 159-192.

2. Burns D., E. Dybing, N. Gray, S. Hecht, C. Anderson, T. Sanner, R. O’Connor, M. Djordjevic, C. Dresler, and P. Hainaut: Mandated Lowering of Toxicants in Cigarette Smoke: A Description of the World Health Organization TobReg Proposal; Tob. Control 17 (2008) 132-141.

3. Baker, R.R.: Smoke Generation Inside a Burning Cigarette: Modifying Combustion to Develop Cigarettes That May be Less Hazardous to Health; Prog. Energ. Combust. 32 (2006) 373-385.

4. Baker, R.R.: Smoke Chemistry; Chapter 12 in: Tobacco: Production, Chemistry and Technology, edited by D.L. Davis and M.T. Nielsen, Blackwell Science, Oxford, UK, 1999, 398-439.

5. Borgerding, M. and H. Klus: Analysis of Complex Mixtures - Cigarette Smoke; Exp. Toxicol. Pathol. 57 (2005) 43-73.

6. Perfetti, T.A. and A. Rodgman: The Complexity of Tobacco and Tobacco Smoke; Beitr. Tabakforsch. Int. 24 (2011) 215-232.

7. Rodgman, A. and T.A. Perfetti: The Chemical Components of Tobacco and Tobacco Smoke; CRC Press, Boca Raton, FL, USA (2013).

8. Egerton, A., K. Gugan, and F. Weinberg: The Mechanism of Smouldering in Cigarettes; Combust. Flame. 7 (1963) 63-78.

9. Lendvay, A.T. and T.S. Laszlo: Cigarette Peak Coal Temperature Measurements; Beitr. Tabakforsch. 7 (1974) 276-281.
10. Laszlo, T.S. and F.M. Watson III: A Scanning Infrared Technique for Cigarette Coal Peak Temperature Measurements; Beitr. Tabakforsch. 7 (1974) 269-275.

11. Baker, R.R.: Temperature Distribution Inside a Burning Cigarette; Nature 247 (1974) 405-406.

12. Baker, R.R.: Temperature Variation Within a Cigarette Combustion Coal During the Smoking Cycle; High Temp. Sci. 7 (1975) 236-247.

13. Muramatsu, M.: Studies on the Transport Phenomena in Naturally Smoldering Cigarettes; Kenkyu Hokoku, Scientific Papers of the Central Research Institute, Japan Tobacco \& Salt Public Corporation, 1981.

14. Green, C.R., J.N. Schumacher, R.A. Lloyd Jr, and A. Rodgman: Comparisons of the Composition of Tobacco Smoke and the Smokes From Various Tobacco Substitutes; Beitr. Tabakforsch. Int. 22 (2007) 258-289.

15. Green, C.R., J.N. Schumacher, and A. Rodgman: The Expansion of Tobacco and Its Effect on Cigarette Mainstream Smoke Properties; Beitr. Tabakforsch. Int. 22 (2007) 317-345.

16. Norman, A.: Cigarette Design and Materials; Chapter 11B in: Tobacco: Production, Chemistry and Technology, edited by D.L. Davis and M.T. Nielsen, Blackwell Science, Oxford, UK, 1999, pp. 353-387.

17. Branton, P.J., K.G. McAdam, M.G. Duke, C. Liu, M. Curle, M. Mola, C.J. Proctor, and R.H. Bradley: Use of Classical Adsorption Theory to Understand the Dynamic Filtration of Volatile Toxicants in Cigarette Smoke by Active Carbons; Adsorpt. Sci. Technol. 29 (2011) 117-138.

18. Scherer, G.: Smoking Behaviour and Compensation: A Review of the Literature; Psychopharmacology 145 (1999) 1-20.

19. Baker, R.R. and L.S. Lewis: A Review of the Incidence and Consequences of Cigarette Filter Vent Blocking Among Smokers; Beitr. Tabakforsch. Int. 19 (2001) 209-228.

20. ECLIPSE Expert Panel: A Safer Cigarette? A Comparative Study. A Consensus Report; Inhal. Toxicol. 12, Suppl. 5 (2000) 1-48.

21. International Organisation for Standardization (ISO): ISO/NP TR 19478. ISO and Health Canada Intense Smoking Parameters -- Results of an International Machine Smoking Study; ISO, Geneva, Switzerland, 2014.

22. Riley, D.S, D.G. Drake, R.R. Baker, and D.P. Robinson: Non-Darcy Flow and Diffusion in a Tobacco Rod; Physicochem. Hydrodyn. 7 (1986) 255-279.

23. Li, B., H.R. Pang, J. Xing, B. Wang, C. Liu, K.G. McAdam, and J.P. Xie: Effect of Reduced Ignition Propensity Paper Bands on Cigarette Burning Temperatures; Thermochim. Acta 579 (2014) 93-99.

24. Li, B., H.R. Pang, L.C. Zhao, B. Wang, C. Liu, K.G. McAdam, and D.S. Luo: Quantifying Gas-Phase Temperature Inside a Burning Cigarette; Ind. Eng. Chem. Res. 53 (2014) 7810-7820.

25. Rosin, P. and E. Rammler: The Laws Governing the Fineness of Powdered Coal; J. Inst. Fuel. 7 (1933) 29-36.

26. International Organization for Standardization (ISO): International Standard ISO 3308:2000. Routine Analytical Cigarette-Smoking Machine -- Definition and 
Standard Conditions; 4th Edition, ISO, Geneva, Switzerland, 2000.

27. Baker, R.R. and M. Dixon: The Retention of Tobacco Smoke Constituents in the Human Respiratory Tract; Inhal. Toxicol. 18 (2006) 255-294.

28. Stotesbury, S.J., H. Digard, L.J. Willoughby, and A. Couch: The Pyrolysis of Tobacco Additives as a Means of Predicting Their Behaviour in A Burning Cigarette; Beitr. Tabakforsch. Int. 18 (1999) 147-163.

29. Stotesbury, S.J., L.J. Willoughby, and A. Couch: Pyrolysis of Cigarette Ingredients Labelled with Stable Isotopes; Beitr. Tabakforsch. Int. 19 (2000) 55-64.

30. Hertz, R., T. Streibel, C. Liu, K. McAdam, and R. Zimmermann: Microprobe Sampling - Photo Ionization-Time-of-Flight Mass Spectrometry for In Situ Chemical Analysis of Pyrolysis and Combustion Gases: Examination of the Thermo-Chemical Processes Within a Burning Cigarette; Anal. Chim. Acta. 714 (2012) 104-113.

31. University of Kentucky: College of Agriculture, Reference Cigarette Program; available at: http://www2.ca. uky.edu/refcig (accessed December 2014).

\section{Corresponding author:}

Bin $\mathrm{Li}$

Zhengzhou Tobacco Research Institute of CNTC

Zhengzhou 450001, China

E-mail:lib@ztri.com.cn 